SUBJECT AREAS: ELECTROCATALYSIS

CATALYST SYNTHESIS

FUEL CELLS

NANOWIRES

Received

27 December 2012

Accepted

21 January 2013

Published

25 March 2013

Correspondence and requests for materials should be addressed to X.S. (xsun@eng.uwo.

* These authors contributed equally to this work. \title{
with Extremely High Activity and Stability for Oxygen Reduction Reaction
}

\author{
Gaixia Zhang ${ }^{1,2 *}$, Shuhui Sun ${ }^{1,2 *}$, Mei Cai ${ }^{3}$, Yong Zhang' ${ }^{1}$ Ruying Li' \& Xueliang Sun ${ }^{1}$
}

\footnotetext{
'Department of Mechanical and Materials Engineering, the University of Western Ontario, London, Ontario, N6A 5B9, Canada,

${ }^{2}$ Institut National de la Recherche Scientifique -Énergie, Matériaux et Télécommunications, Varennes, QC J3X 1S2, Canda,

${ }^{3}$ General Motors Global Research and Development Center, Warren, Michigan, 48090-9055, USA.
}

Controlling the morphology of Pt nanostructures can provide opportunities to greatly increase their activity and stability. Porous dendritic Pt nanotubes were successfully synthesized by a facile, cost-effective aqueous solution method at room temperature in large scale. These unique structures are porous, hollow, hierarchical, and single crystalline, which not only gives them a large surface area with high catalyst utilization, but also improves mass transport and gas diffusion. These novel Pt structures exhibited significantly improved catalytic activity (4.4 fold) for oxygen reduction reaction (ORR) and greatly enhanced durability ( 6.1 fold) over that of the state-of-the-art commercial $\mathrm{Pt} / \mathrm{C}$ catalyst. This work provides a promising approach to the design of highly efficient next-generation electrocatalysts.

latinum (Pt) is the most effective catalyst for both hydrogen oxidation and oxygen reduction in proton exchange membrane fuel cells (PEMFCs) ${ }^{1,2}$. However, the high cost and insufficient stability of Pt catalysts pose a severe challenge to the commercialization of PEMFCs ${ }^{3}$. It is generally accepted that the chemical and physical properties of the metal nanostructures can be tuned by controlling their shape, size, and crystallinity. To date, many approaches have been developed to prepare Pt nanostructures in different shapes to improve their fuel cell performance: for example, multi-octahedrons $s^{4}$, that exhibited a higher specific activity $(2.7$-fold greater, while retaining similar mass activity) and stability (5.9-fold greater) than the state-of the art $\mathrm{Pt} / \mathrm{C}$ catalyst; nanocubes that showed twice the specific activity of that of the commercial catalyst ${ }^{5}$ and were also found to be 4 times more active than polyhedrons or truncated cubes $^{6}$; nanowires that were 3 times more active and 5 times more stable than the Pt/C commercial catalyst ${ }^{7-9}$; and other shapes ${ }^{10,11}$. These results show that controlling the morphology of Pt nanostructures provides great opportunities to improve fuel cell performance. Among those materials, hollow nanostructures have attracted significant attention because their properties are distinct from those of their solid counterparts, including their large surface area, low density, rich surface chemistry, high catalytic activity, and low $\cos ^{12-16}$. As a result of the creation of more cavities and holes and the assembly of a greater number of nanoparticles, porous hollow Pt nanostructures ${ }^{16-19}$ possess a much larger surface area and more catalytically active points for electro-catalysis; therefore, they have drawn particular interest for fuel cell application $s^{16-20}$. Recently, extensive interest has been expressed in the synthesis of hierarchical structures that are, ideally, connected through low dimensional materials with particularly structured junctions. This interest has arisen because such hierarchical materials not only exhibit excellent mechanical strengths and electrical conductivities that are superior to those of their constituents while maintaining comparable surface areas, but they also solve the problem of nanomaterial agglomeration ${ }^{21-24}$. There have been advances in the synthesis of hollow and porous $^{12-20,25,26}$ Pt nanostructures, most of which have focused on 1D Pt tubes, but such development has been rare for hierarchical porous Pt tubes. Therefore, the design of more complex Pt nanostructures by combining the multi-advantages of porous, hollow, and hierarchical structures to obtain significantly improved catalyst activity and stability are highly desired, however remains grand challenge.

In this paper, we describe a novel approach to address both the activity and stability issues synergistically by using porous dendritic Pt nanotubes as fuel cell catalysts. Such hierarchical catalysts are expected to integrate several different functionalities (hollow, dendrites, porous) in one structure, which is difficult to accomplish in a single morphology. The synthesis strategy is based on the galvanic replacement reaction between $\mathrm{Ag}$ dendrites and $\mathrm{H}_{2} \mathrm{PtCl}_{6}$ that is conducted in surfactant-free, environmentally friendly aqueous solution at room temperature. Compared with the most widely used commercial catalyst, which is made of Pt nanoparticles $(2-5 \mathrm{~nm})$ 


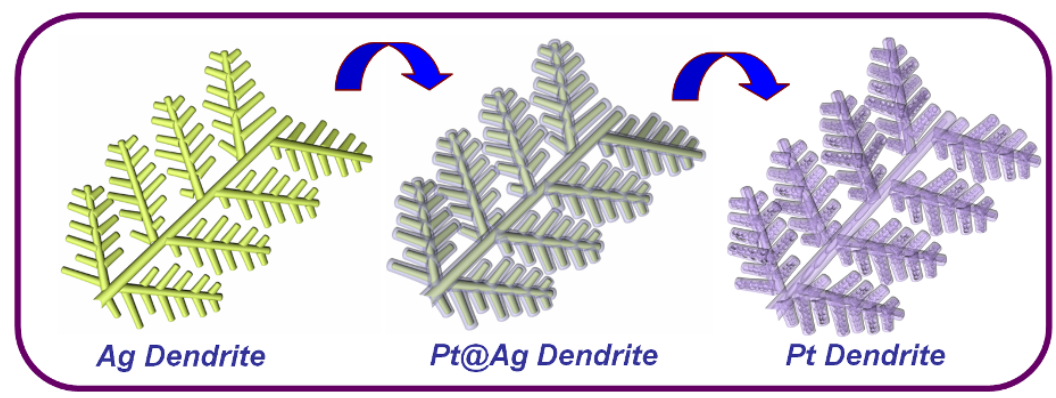

Figure $1 \mid$ Schematic illustration of the formation of the Pt dendritic nanotubes originating from the Ag dendrite nanostructure.

supported on carbon-particle aggregates, the micrometer-long porous dendritic Pt tubes hold great potential to significantly improve the catalytic activity and stability due to the following reasons: 1) they are self-supporting, eliminating the carbon corrosion problem that potentially causes migration of the Pt nanoparticles, coalescence, and even detachment from the catalyst system ${ }^{18} ; 2$ ) their hierarchical structure has stronger mechanical properties and is less vulnerable to dissolution and aggregation ${ }^{21}$; 3 ) their porous, hollow and hierarchical structure, in addition to providing a large surface area with high catalyst utilization, can also improve mass transport and gas diffusion ${ }^{28,29}$; 4) importantly, the continuous shell of dendritic tubes is composed of numerous assembled Pt nanocrystals with the same crystal orientation, which more closely resemble to the highly active single-crystalline bulk catalyst surface of $\mathrm{Pt}^{29,30}$. These new achievements, to the best of our knowledge, have not yet been reported in the literature.

\section{Results}

Porous Pt dendritic nanotubes were synthesized by a two-step method based on galvanic replacement reactions (Figure 1). In the first step, Ag dendrites were synthesized by the replacement reaction between commercial $\mathrm{Mg}$ powder and $\mathrm{AgNO}_{3}$ in aqueous solution, based on the following reaction:

a

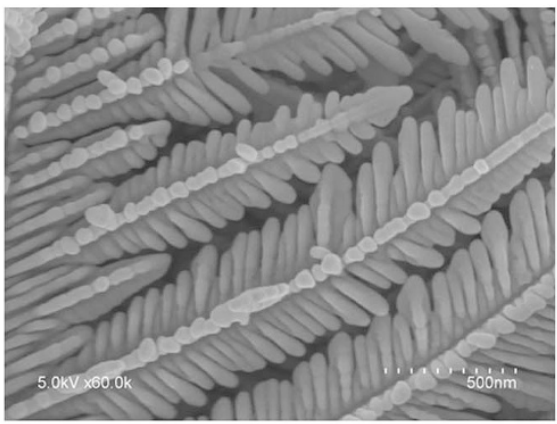

C

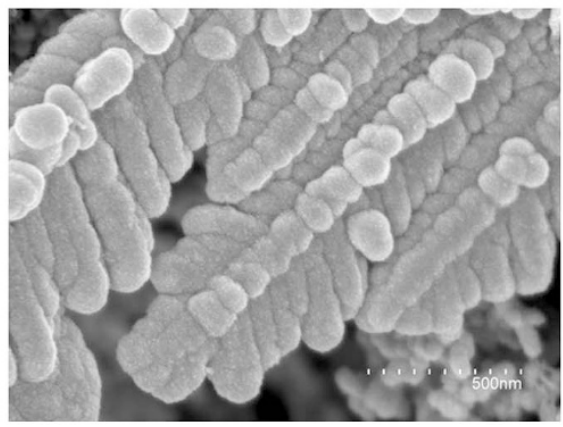

$$
M g_{(s)}+2 A g_{(a q)}^{+} \rightarrow M g_{(a q)}^{2+}+2 A g_{(s)}
$$

The morphological and structural characterization of Ag dendrites is shown in Figure S1 (Supplementary Information) and Figure 2. The low-magnification scanning electron microscope (SEM) image and the energy-dispersive X-ray spectrum (EDX) (Figure S1) indicate that micrometer long uniform Ag dendrites were successfully synthesized at a large scale. The higher magnification SEM images (Figure 2a and b) clearly show that the dendrite structures have multilevel generations with a long main trunk and many well-aligned side branches (or sub-branches, as indicated by a white arrow in Figure $2 b$ ), resembling fractal leaves. Generally, the lengths of the trunks and the (sub-)branches are several tens of micrometers and several hundreds of nanometers, respectively. However, all of the diameters of the trunks, branches, and sub-branches have a similar size of approximately $40 \mathrm{~nm}$. In the second step, the as-synthesized $\mathrm{Ag}$ dendrites were then used as templates for the synthesis of $\mathrm{Pt}$ dendritic tubes through a galvanic replacement reaction, as illustrated in Figure 1, according to the following formula:

$$
4 \mathrm{Ag}_{(s)}+\left(\mathrm{PtCl}_{6}\right)_{(a q)}^{2-} \rightarrow \mathrm{Pt}_{(s)}+4 \mathrm{AgCl}_{(s)}+2 \mathrm{Cl}_{(a q)}^{-}
$$

After the completion of the reaction, the SEM image (Figure 2c) reveals that similar dendritic structures were formed but with

b

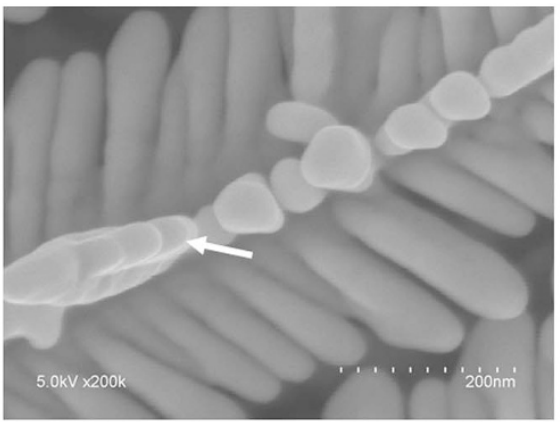

d

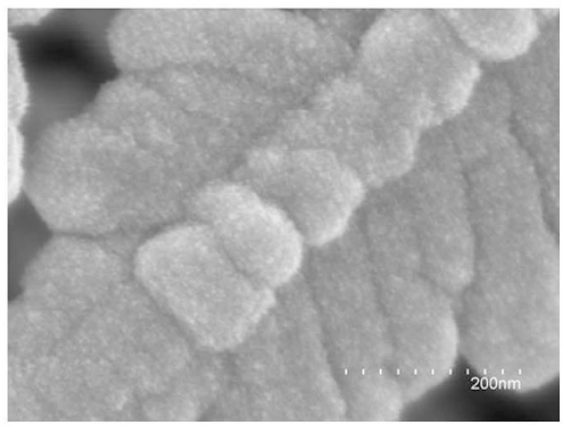

Figure $2 \mid$ SEM characterization of Ag dendrites and porous dendritic Pt tubes. SEM images (a, b) of Ag dendrites and (c, d) of porous dendritic Pt nanotubes, at different magnifications. Platinum exactly replicates the dendritic structure of the Ag with relatively larger branches and a rough surface. 
relatively greater branch diameters (ca. $46 \mathrm{~nm}$ ). This is consistent with the so-called Kirkendall effect that has been used to illustrate the outward growth of hollow structures ${ }^{31-34}$. The surface of dendrites becomes rough and develops a porous structure that is composed of numerous assembled tiny nanoparticles (Figure 2d). The EDX spectrum, shown in Figure S2, confirms the formation of pure platinum. Significantly, the amount of product can be easily scaled up to gram scale (e.g. $10 \mathrm{~g} \mathrm{Ag}$ dendrites and $1.5 \mathrm{~g}$ Pt dendritic tubes, Figure S3) by simply multiplying the amounts of reactants, which is important for the commercialization of PEM fuel cells.

The Pt products were further characterized by transmission electron microscope (TEM). It is found that the centers of the dendritic Pt nanostructures are brighter than the edges, clearly depicting a tubular morphology (Figure 3a), and the wall thickness of the Pt nanotube branches is $\sim 2.5 \mathrm{~nm}$ (Fig. $3 \mathrm{~b}-\mathrm{d}$ ), which is slightly larger than the theoretical calculated value of $2.0 \mathrm{~nm}$ if the wall is assumed to be fully condensed (see the calculation shown in Supplementary Information Figure S4). The high-resolution TEM (HRTEM) image (Fig. 3b) shows the representative morphology of an individual branch of Pt dendrites, which indicates that the shells of the nanotubes consist of tiny Pt nanocrystals. Interestingly, these Pt nanocrystals assemble to form a continuous shell with single-crystal structure (as indicated by the red dot line). Due to the large diameter of the tubes (about $46 \mathrm{~nm}$, with low surface curvature), the shell more closely resembles to a bulk single-crystal surface of $\mathrm{Pt}$ that has an extremely high catalytic activity ${ }^{29,30}$. The lattice spacing along the axis of the nanotube branch is ca. $0.23 \mathrm{~nm}$, corresponding to the interplanar spacing of $\{111\}$ planes in the fcc Pt. The HRTEM image shown in Figure $3 \mathrm{c}$ was taken from a thin part of a dendritic branch. This image clearly shows a more porous structure in the thinner part

a

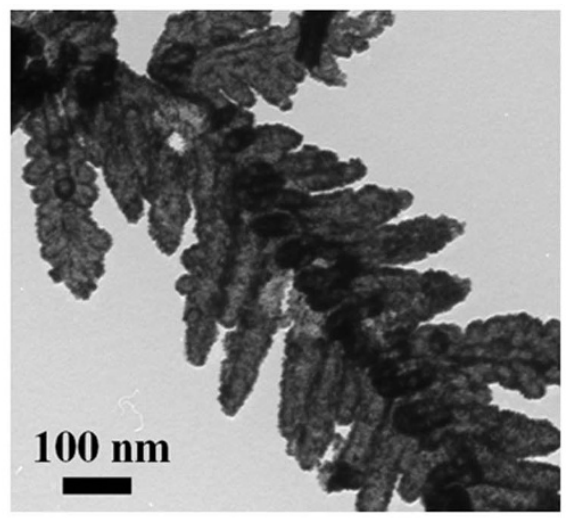

C

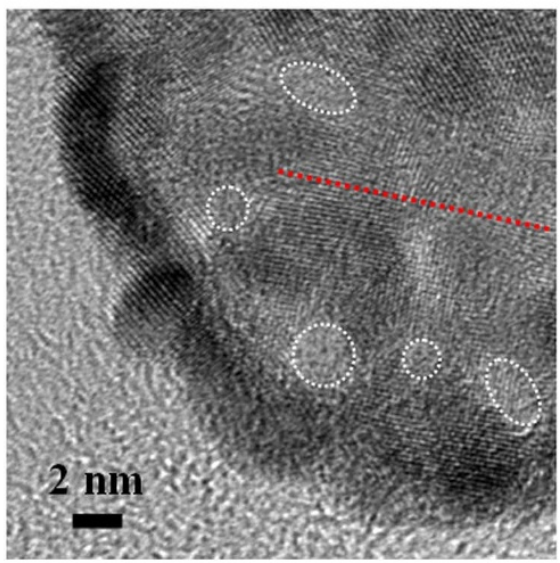

of the shell, as indicated by the white dotted circles, and most of the small nanocrystals aligned with the same crystal orientation (as indicated by the red dot line). Figure 3d was taken from the boundary between two Pt nanotube branches; interestingly, different tubes have the same crystal orientation (as indicated by the red dot line). This phenomenon may be caused by the epitaxial growth of the $\mathrm{Pt}$ that was templated from the single crystalline Ag dendrite. The detailed Ag structural characterization, including the crystallinity and the (sub)branch growth directions, are presented in Figure S5, which demonstrates that the Ag dendritic single crystal grows along a preferential direction of $\langle 111\rangle$. The small mismatch in the lattice constants between $f c c \operatorname{Ag}(4.08 \AA)$ and $f c c \operatorname{Pt}(3.92 \AA)$ favorites the epitaxial growth of Pt on Ag dendrites, therefore forming continuous $\mathrm{Pt}$ shells. In addition, it should be noted that these TEM images were obtained after the removal of unreacted Ag template by acid wash and the strong sonication during TEM sample preparation process. The Pt shells remain uncollapsed as hollow nanotubes, which suggests the excellent mechanical stability of the dendritic hollow structures.

To study the transformation process from $\mathrm{Ag}$ dendrites to $\mathrm{Pt}$ dendritic nanotubes, samples were taken from the solution as a function of reaction time, and the morphology and composition of these samples were analyzed by TEM and powder X-ray diffraction (XRD). The TEM images show different stages of the galvanic replacement reaction between $\mathrm{Ag}$ dendrites and $\mathrm{H}_{2} \mathrm{PtCl}_{6}$ (Figure S6). After $1 \mathrm{~min}$ of reaction, some Pt nanoparticles began to appear on the outer surface of the Ag dendrites, and some parts of Ag dendrites started to get porous and hollow (as indicated by arrows in Figure S6b). This was because that four $\mathrm{Ag}$ atoms were consumed to form only one $\mathrm{Pt}$ atom, as defined by the stoichiometric relationship between Ag and

$\mathrm{b}$

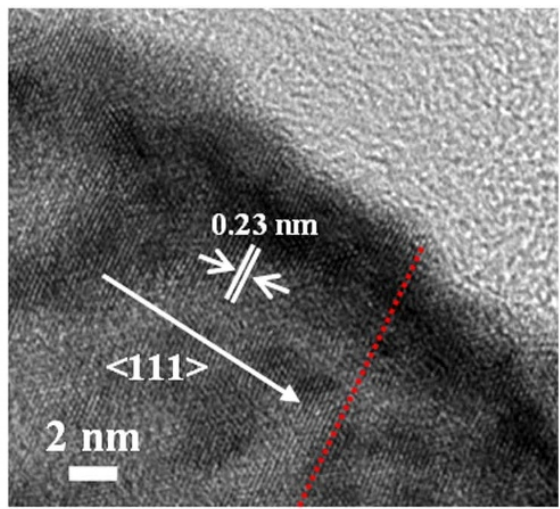

d

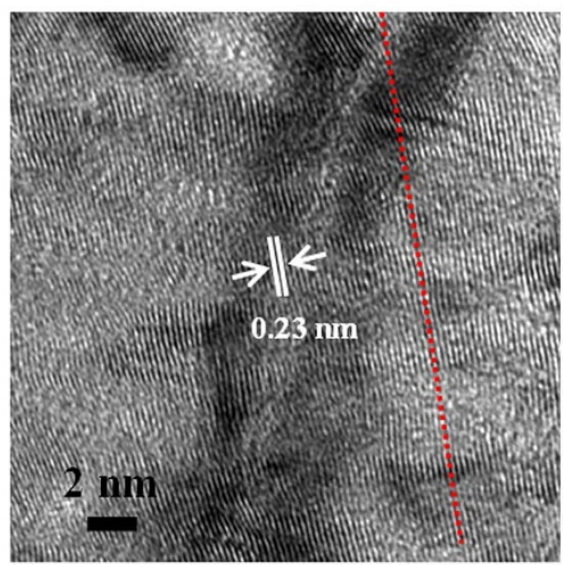

Figure 3 TEM characterization of porous dendritic Pt tubes. (a) TEM images of the dendritic Pt tubes. (b, c) HRTEM images taken from different areas of the Pt tubes with relatively thick or thin wall thicknesses, respectively. (d) HRTEM image of the boundary between two Pt nanotubes. Dendritic Pt nanotubes exhibited a well-aligned crystalline nature. 
$\mathrm{H}_{2} \mathrm{PtCl}_{6}$ (Eq. (2)), leaving behind vacancies in the template as the galvanic replacement reaction proceeds. After $8 \mathrm{~min}$ and $12 \mathrm{~min}$ of reaction, the whole dendrites get more transparent than the solid Ag templates, indicating the formation of porous and hollow Pt tubes (Figure S6c,d). In addition, their surface become rougher (as indicated by the arrows) than the smooth surface of original Ag dendritic template (Figure S6a), indicating that Pt gradually increased and evolved into nanoshells around the Ag templates. Finally, high quality dendritic porous $\mathrm{Pt}$ nanotubes with uniform sizes were obtained as a result of complete consumption of Ag templates after 24 hours.

Further, the corresponding XRD patterns (Figure 4) of the above samples also indicate the evolution stages from Ag to pure Pt. Figure 4a shows the purity of the Ag dendrites (JCPDS, 04-0783), with peaks located at $38.12,44.27$ and 64.43 that can be assigned to the (111), (200) and (220) planes of Ag, respectively. After an $8 \mathrm{~min}$ reaction, the $\mathrm{Ag}$ peaks are dramatically reduced, and obvious $\mathrm{AgCl}$ peaks appear (Figure $4 \mathrm{~b}$ ). When the reaction proceeded for $12 \mathrm{~min}$, the peak ratio of $\mathrm{Ag}$ to $\mathrm{AgCl}$ decreased. The Pt peaks were not obvious, mainly because the atomic ratio of $\mathrm{Pt}$ to $\mathrm{AgCl}$ in the product is 1:4 (according to the formula $\left(\mathrm{PtCl}_{6}\right)^{2-}+4 \mathrm{Ag} \rightarrow \mathrm{Pt}+4 \mathrm{AgCl}+$ $2 \mathrm{Cl}^{-}$), and $\mathrm{Pt}$ is an element with heavy atoms. Therefore, the XRD pattern shows a strong $\mathrm{AgCl}$ signal (Figure 4c). When the samples were washed using saturated $\mathrm{NaCl}$ and $\mathrm{HNO}_{3}$ to eliminate the $\mathrm{AgCl}$ and $\mathrm{Ag}$, respectively, pure $\mathrm{Pt}$ was obtained, as shown in Figure $4 \mathrm{~d}$. When making a careful comparison with the XRD patterns of the 8 and 12 min products, the contribution of the Pt (Figure S7) is visible. In fact, the peaks located at 38.8 and 45.0 are composite peaks, composed of two peaks at 38.12 (Ag 111) and 39.76 (Pt 111), as well as 44.28 (Ag 200) and 46.24 (Pt 200), respectively. The intensities of these two peaks decrease, and the corresponding peak positions shift positively with reaction time, indicating the gradual sacrifice of Ag and formation of Pt.

The electrochemical properties of the porous Pt dendritic tubes were evaluated, and the results were compared with those obtained for a commercial Pt/C catalyst (E-TEK, $30 \mathrm{wt} \% \mathrm{Pt}$, made of Pt nanoparticles on a carbon support) and Pt black. Figure 5a shows the cyclic voltammetry (CV) curves of these three catalysts recorded at room temperature in $\mathrm{N}_{2}$ purged $0.5 \mathrm{M} \mathrm{H}_{2} \mathrm{SO}_{4}$ solution with a sweep rate of $50 \mathrm{mV} / \mathrm{s}$. All three $\mathrm{CV}$ curves exhibited strong peaks associated with hydrogen adsorption/desorption below $0.4 \mathrm{~V}$ (vs. RHE) and Pt oxide formation/reduction above that value. The

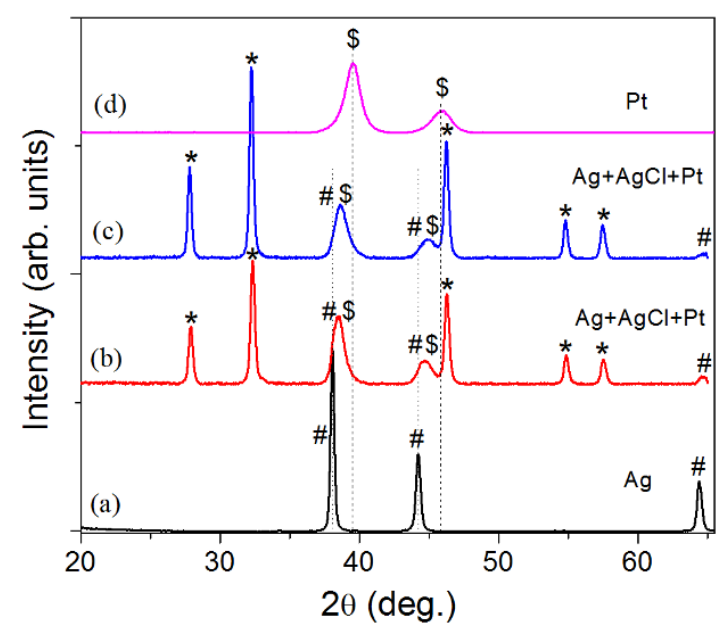

Figure $4 \mid$ XRD characterization. XRD patterns showing the stages of evolution from pure $\mathrm{Ag}$ to pure $\mathrm{Pt}$, as a function of reaction time for (a) $0 \mathrm{~min}$, (b) $8 \mathrm{~min}$, (c) $12 \mathrm{~min}$, and (d) final product. The pound sign (\#) indicates the silver diffraction peaks; the asterisk sign (*) indicates the silver chloride diffraction peaks; and the dollar sign (\$) indicates the platinum peaks. electrochemical active surface areas (ECSA) were calculated by measuring the charge $\left(\mathrm{Q}_{\mathrm{H}}\right)$ associated with the adsorbed hydrogen monolayer $\left(\mathrm{H}_{\mathrm{ads}}, \mathrm{H}^{+}+\mathrm{e}^{-}=\mathrm{H}_{\mathrm{ads}}\right.$, where $\mathrm{H}_{\text {ads }}$ refers to the underpotentially deposited hydrogen) between $0<\mathrm{E}<0.4 \mathrm{~V}$ (where $\mathrm{E}$ is the applied potential) and assuming that $\mathrm{Q}_{\mathrm{ref}}=0.21 \mathrm{mC} / \mathrm{cm}^{2}$ for the adsorption of a hydrogen monolayer ${ }^{43,44}$, corresponding to a surface density of $1.3 \times 10^{15} \mathrm{Pt}$ atoms per $\mathrm{cm}^{2}$. The specific ECSA of the $\mathrm{Pt}$ dendritic tubes was $23.3 \mathrm{~m}^{2} / \mathrm{g} \mathrm{Pt}$, which is 1.4 times greater than that of Pt black $\left(16.3 \mathrm{~m}^{2} / \mathrm{g} \mathrm{Pt}\right)$, but is around half $(53 \%)$ that of commercial Pt/C catalyst $\left(43.8 \mathrm{~m}^{2} / \mathrm{g} \mathrm{Pt}\right)$. Interestingly, a careful inspection of the voltammograms in Figure 5 a reveals that the morphological change of the Pt nanostructures from solid particles (0D) to dendritic hollow tubes (3D) also greatly altered their ability to adsorb hydroxyl species $\left(\mathrm{OH}_{\mathrm{ad}}\right)$, which has an inhibiting (site blocking) effect on the ORR activity. There are significantly positive shifts, $71 \mathrm{mV}$ and $95 \mathrm{mV}$, respectively, in hydroxyl adsorption/desorption on Pt dendritic nanotubes than that on $\mathrm{Pt} / \mathrm{C}$ and $\mathrm{Pt}$ black catalysts, indicating a slower hydroxyl adsorption rate and faster hydroxyl desorption rate on the Pt dendritic tube surface, and better ORR activity as a result ${ }^{45}$. Moreover, in agreement with the onset potential of adsorption, on $\mathrm{Pt}$ dendritic nanotubes, the fractional coverage by $\mathrm{OH}_{\mathrm{ad}}\left(\Theta_{\mathrm{OHad}}\right)$ was dramatically reduced at all potential range $>0.6 \mathrm{~V}$ compared to that of $\mathrm{Pt} / \mathrm{C}$ and Pt black (Figure 5b). The much lower $\mathrm{OH}_{\mathrm{ad}}$ coverage on the Pt dendritic nanotubes than on the Pt/C and Pt black catalysts contributes to enhanced ORR activity and stability ${ }^{46,47}$.

Figure $5 \mathrm{c}$ shows the ORR polarization curves for porous Pt dendritic tubes, Pt black and $\mathrm{Pt} / \mathrm{C}$ (E-TEK) catalysts obtained at room temperature in $\mathrm{O}_{2}$-saturated $0.5 \mathrm{M} \mathrm{H}_{2} \mathrm{SO}_{4}$ with a $\mathrm{GC}$ rotating disk electrode (RDE) at $1600 \mathrm{rpm}$. The half-wave potential for the porous Pt dendritic tubes shows an obvious positive shift relative to those for both the Pt black and $\mathrm{Pt} / \mathrm{C}$ catalysts, indicating a higher catalytic activity for the Pt dendritic tubes than those of the other two commercial Pt nanoparticle-based catalysts. Both the mass activity and specific activity are good indicators of the quality of an electrocatalyst. As shown in Figure 5d, the Pt dendritic tubes exhibited a mass activity of $0.21 \mathrm{~mA} / \mu \mathrm{g} \mathrm{Pt}$ at $0.9 \mathrm{~V}$ (vs. RHE), which is 2.33 times that of the Pt/C (E-TEK) catalyst $(0.09 \mathrm{~mA} / \mu \mathrm{g} \mathrm{Pt})$ and 5.25 times that of the Pt black catalyst $(0.04 \mathrm{~mA} / \mu \mathrm{g} \mathrm{Pt})$. Interestingly, this improvement occurred in spite of the approximately 50\% lower Pt active surface area of the $\mathrm{Pt}$ dendritic tube catalyst. On the basis of both the mass activity and the active surface area, a specific ORR activity of $0.901 \mathrm{~mA} / \mathrm{cm}^{2} \mathrm{Pt}$ for the porous Pt dendritic tubes was obtained at $0.9 \mathrm{~V}$, which is higher than the US department of energy (DOE) 2015 target for the specific activity $\left(0.720 \mathrm{~mA} / \mathrm{cm}^{2} \mathrm{Pt}\right)^{48}$, and it is 4.40 -fold and 3.68-fold greater than those of the E-TEK Pt/C catalyst $\left(0.205 \mathrm{~mA} / \mathrm{cm}^{2} \mathrm{Pt}\right)$ and the Pt black catalyst $\left(0.245 \mathrm{~mA} / \mathrm{cm}^{2} \mathrm{Pt}\right)$, respectively. This improvement agrees well with those reported for Pt tubes obtained under full-cell operating conditions ${ }^{7}$.

The accelerated durability tests (ADT) of the catalysts were conducted by applying linear potential sweeps between 0.6 and $1.2 \mathrm{~V}$ (vs. $\mathrm{RHE}$ ) in $\mathrm{O}_{2}$-saturated $0.5 \mathrm{M} \mathrm{H}_{2} \mathrm{SO}_{4}$ solution at room temperature with a scan rate of $50 \mathrm{mV} / \mathrm{s}$. After 4,000 cycles, the $\mathrm{CV}$ measurements showed that the Pt dendritic tube catalyst lost only $11 \%$ of the Pt initial ECSA (Figure 6a,d), whereas the degradations of both Pt nanoparticle-based commercial catalysts were quite severe, with 67.5\% and 52.7\% losses of the initial Pt ECSA for E-TEK Pt/C (Figure 6b,d) and Pt black (Figure 6c,d), respectively. These results indicate that the porous Pt dendritic tube catalyst is 6.1-fold and 4.8fold more stable than the Pt/C and Pt black nanoparticle-based commercial catalyst, respectively.

\section{Discussion}

The similar replacement reaction was extended between $\mathrm{Mg}$ and $\mathrm{H}_{2} \mathrm{PtCl}_{6}$ to synthesize $\mathrm{Pt}$, according to the following equation:

$$
2 M g_{(s)}+\left(P t C l_{6}\right)_{(a q)}^{2-} \rightarrow P t_{(s)}+2 M g_{(a q)}^{2+}+6 C l_{(a q)}^{-}
$$



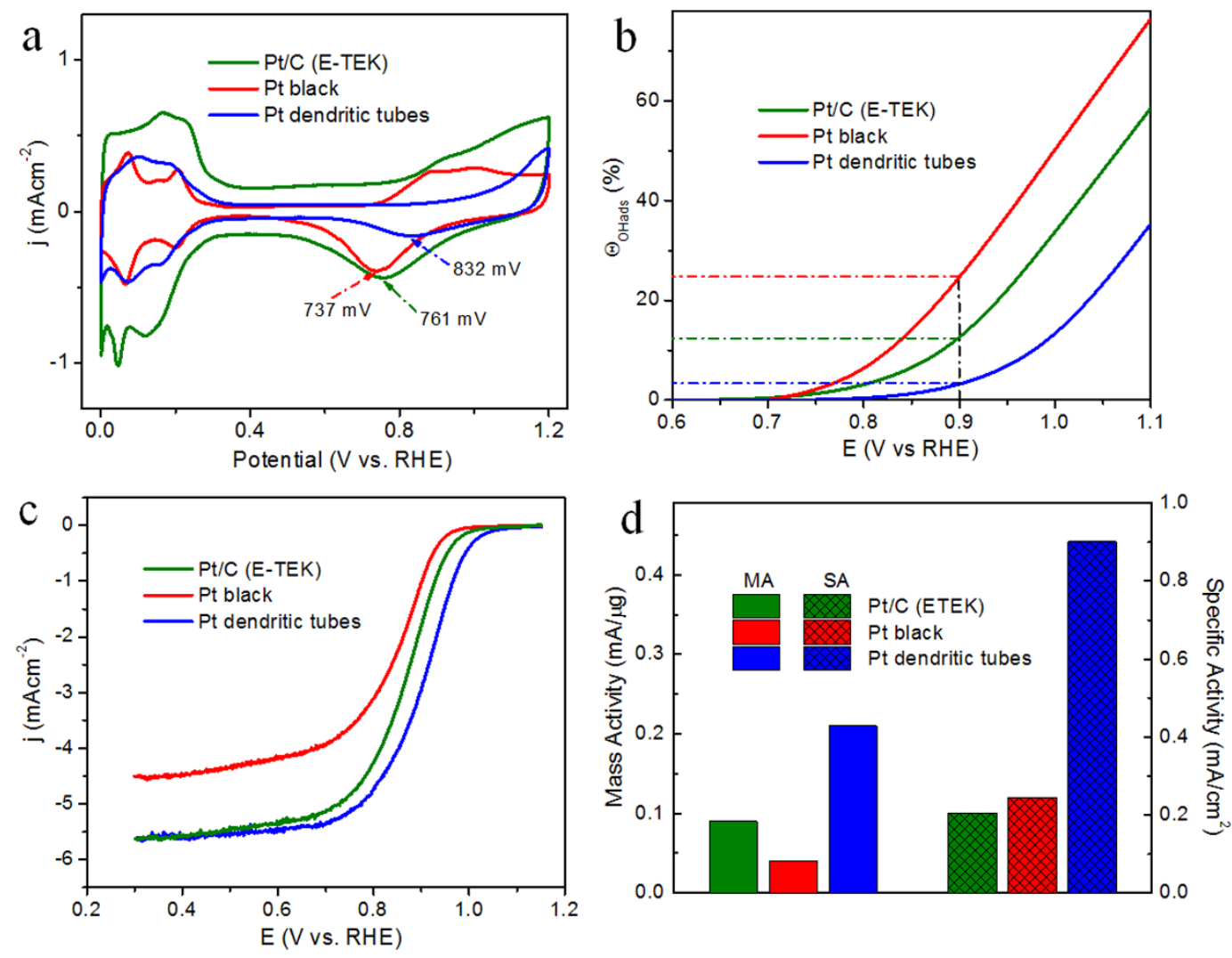

Figure 5 Electrochemical evaluation. (a) CV curves and (b) hydroxyl surface coverage $\left(\Theta_{\mathrm{OH}}\right)$ for three types of catalysts: Pt dendritic tubes (blue line), Pt black (red line) and Pt/C (E-TEK, green). The much lower $\mathrm{OH}_{\mathrm{ad}}$ coverage on the dendritic Pt nanotubes than on the Pt/C and Pt black catalysts could contribute to the enhanced ORR activity. (c) Polarization curves for ORR of the Pt dendritic tube (blue), Pt black (red line) and Pt/C (E-TEK, green, line) catalysts in $\mathrm{O}_{2}$-saturated $0.5 \mathrm{M} \mathrm{H}_{2} \mathrm{SO}_{4}$ solution at room temperature (1600 rpm, sweep rate $10 \mathrm{mV} / \mathrm{s}$ ). (d) Mass activity and specific activity at $0.9 \mathrm{~V}$ (vs. RHE) for the three catalysts. At $0.9 \mathrm{~V}$ (vs. RHE), Pt dendritic tubes were 2.33 times and 5.25 times more active, on the basis of equivalent Pt mass, than Pt/C and Pt black catalysts, respectively. Furthermore, the porous Pt dendritic tubes exhibited a higher specific ORR activity $\left(0.901 \mathrm{~mA} / \mathrm{cm}^{2} \mathrm{Pt}\right)$ than the US DOE $2015 \operatorname{target}\left(0.720 \mathrm{~mA} / \mathrm{cm}^{2} \mathrm{Pt}\right)$.

The original $\mathrm{Mg}$ particles are irregular in shape and quite large in size $(20-100 \mu \mathrm{m})$, and their surface are rough with some cracks (Figure S8a,b). After the reaction, urchin-like structures that are composed of many Pt nanoparticles were obtained (Figure S8c,d), which is different to the morphology of either original $\mathrm{Mg}$ particles (Figure S8a,b) or Ag dendrites (Figure 2a,b, obtained by $\mathrm{Mg}$ and $\mathrm{AgNO}_{3}$ ). Previously, we have given a detailed observation on morphology evolution and explanation on the formation of Ag dendrites obtained from $\mathrm{Mg}$ and $\mathrm{AgNO}_{3}{ }^{35}$. It is worthwhile to clearly understand why so much different structures, including urchins, dendrites, and dentritic tubes, were obtained via similar replacement reactions involving different precursors $\left(\mathrm{Mg}\right.$ and $\mathrm{H}_{2} \mathrm{PtCl}_{6}, \mathrm{Mg}$ and $\mathrm{AgNO}_{3}$, as well as $\mathrm{Ag}$ and $\mathrm{H}_{2} \mathrm{PtCl}_{6}$ ). First, the driving force for the galvanic replacement reaction is the electrical potential difference between two metals. The net potentials in the reactions of $\mathrm{Mg}$ and $\mathrm{H}_{2} \mathrm{PtCl}_{6}$ $(3.40 \mathrm{~V})$ as well as $\mathrm{Mg}$ and $\mathrm{AgNO}_{3}(3.16 \mathrm{~V})$ are much greater than that in the reaction of $\mathrm{Ag}$ and $\mathrm{H}_{2} \mathrm{PtCl}_{6}(0.24 \mathrm{~V})\left[\mathrm{Mg}^{2+} / \mathrm{Mg}\right.$ $(-2.36 \mathrm{~V}), \mathrm{Ag}^{+} / \mathrm{Ag}(0.80 \mathrm{~V})$, and $\mathrm{Pt}^{4+} / \mathrm{Pt}(1.04 \mathrm{~V})$ vs. the standard hydrogen electrode (SHE) $]^{36,37}$. Accordingly, the reaction rates of the former two are much faster than the latter. In addition, because the difference in crystal structures and lattice constants, $\mathrm{Mg}$ (hcp; $\mathrm{a}=$ $3.21 \AA, \mathrm{c}=5.21 \AA)$ and $\mathrm{Ag}(\mathrm{fcc} ; \mathrm{a}=4.08 \AA) / \mathrm{Pt}(\mathrm{fcc} ; \mathrm{a}=3.92 \AA)$ the epitaxial growth of $\mathrm{Ag}$ ( or $\mathrm{Pt}$ ) on $\mathrm{Mg}$ particle templates is not favorable. Therefore, the products of the former two reactions do not follow the morphology of their original templates (the sacrificial metal, $\mathrm{Mg}$ ). Further, comparing the former two reactions $(\mathrm{Mg}+$ $\mathrm{H}_{2} \mathrm{PtCl}_{6}$ and $\mathrm{Mg}+\mathrm{AgNO}_{3}$ ), their net potentials $(3.40 \mathrm{~V}$ vs. $3.16 \mathrm{~V})$ are very close, and thus the reaction rates are quite similar.
However, based on the stoichiometric relationship defined in Eqs. (1) and (3), the molar ratio of $\mathrm{Ag}$ to $\mathrm{Mg}$ is 2:1, while the molar ratio of $\mathrm{Pt}$ to $\mathrm{Mg}$ is 1:2. That means two $\mathrm{Mg}$ atoms could produce, in situ, four Ag atoms, while only one Pt atom, resulting an expending growth for Ag while a shrinking growth for Pt. Therefore, larger size and solid structure for Ag was obtained while smaller structure composed of nanoparticles were formed for Pt. In the case of Pt dendritic tubes, first, the net potential for Eq. (2) is very low $(0.24 \mathrm{~V})$, thus the reaction rate is much slower; second, the fcc lattice constants of Ag and $\mathrm{Pt}$ are very close. These two factors allow i) the continuous $\mathrm{Pt}$ deposition on the surface of Ag template replicating the dendritic structure, and ii) the reconstruction of Pt shells into highly crystalline structure via processes such as Ostwald ripening ${ }^{38}$.

Based on the above analysis, a possible mechanism for the formation of dendrtic Pt tubes is proposed in Figure S9. To simplify, a single branch of dendritic nanotubes is taken as a model for the illustration. As it has been established in previous studies by others and ourselves ${ }^{39-42}$, the replacement reaction starts from the highest energy sites, usually those with steps or point defects or stacking faults on the templates. Our previous work has shown the existence of defects on $\mathrm{Ag}$ dendrites ${ }^{35}$. Once reaction happens on such defects, they will serve as active sites for further replacement reaction (Figure $\mathrm{S} 9 \mathrm{~b})$. The Ag atoms in the interior will diffuse to these reaction sites and react with $\mathrm{H}_{2} \mathrm{PtCl}_{6}$ to generate $\mathrm{Pt}$ atoms. The $\mathrm{Pt}$ atoms prefer to nucleate and grow on the surface of the template because Pt and Ag have the same fcc structure and essentially identical lattice constant, favoring epitaxial growth of $\mathrm{Pt}$ on $\mathrm{Ag}$ dendrites. According to the stoichiometric relationship of $\mathrm{Ag}$ and $\mathrm{H}_{2} \mathrm{PtCl}_{6}$, four $\mathrm{Ag}$ atoms are 

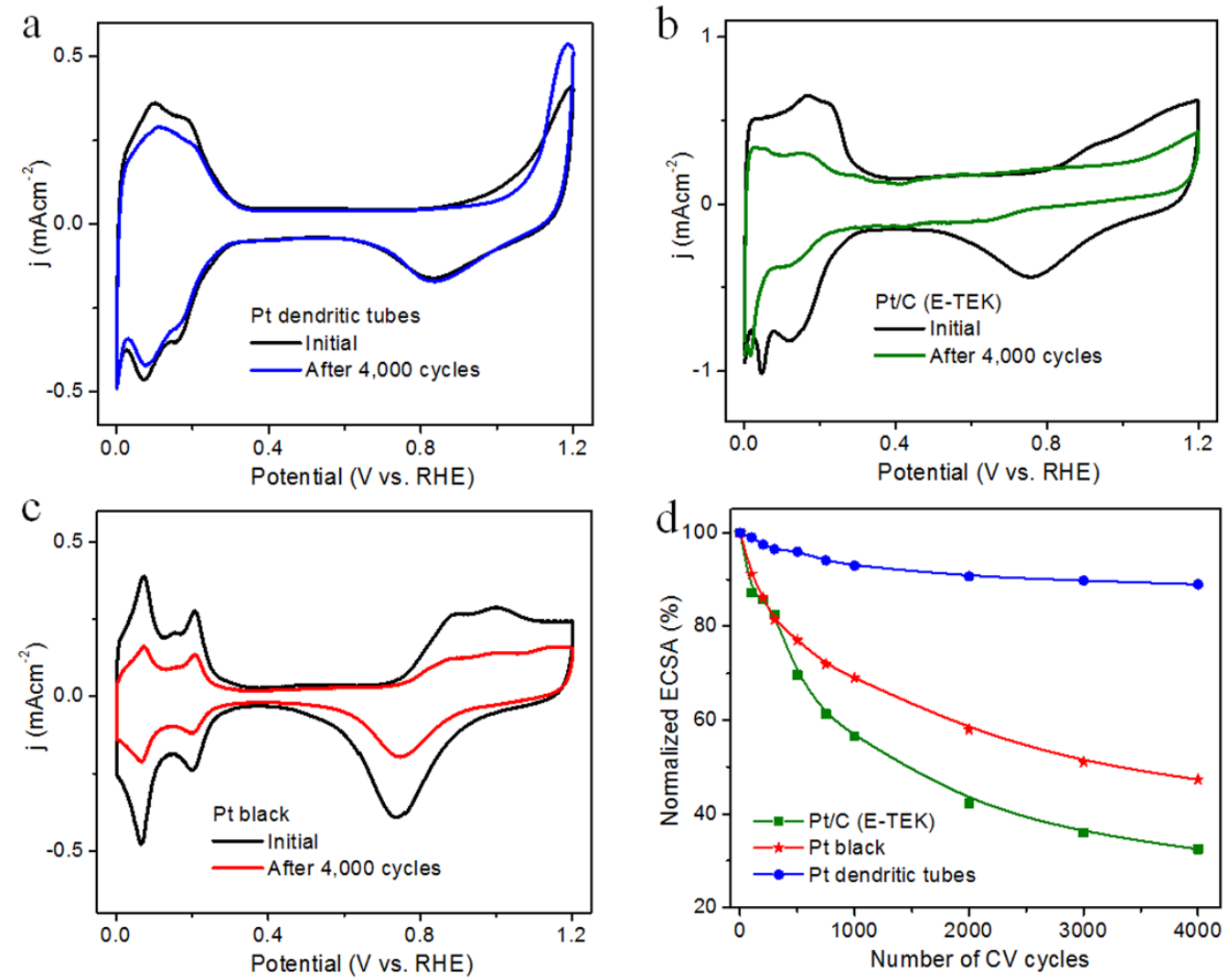

Figure 6 Electrochemical durability evaluation. CV curves for (a) supportless Pt dendritic tubes and (b) Pt/C (E-TEK) and (c) Pt black catalysts before (black curves) and after 4,000 cycle ADT tests (solid curves in blue, green and red, respectively). d) Loss of electrochemical surface area (ECSA) of Pt dendritic tubes (blue line), Pt black (red line) and $\mathrm{Pt} / \mathrm{C}$ (E-TEK, green line) catalysts as a function of cycling numbers in $\mathrm{O}_{2}-\mathrm{purged}_{0.5} \mathrm{M} \mathrm{H}_{2} \mathrm{SO}_{4}$ solution at room temperature (0.6-1.2 V vs. RHE, sweep rate $50 \mathrm{mV} / \mathrm{s})$. The porous Pt dendritic nanotubes were 6.1 -fold and 4.8 -fold more stable than $\mathrm{Pt} / \mathrm{C}$ and Pt black nanoparticle-based commercial catalysts, respectively.

consumed to form only one Pt atom, leaving behind a huge number of vacancies in the template as the replacement reaction proceeds (Figure S9c). These vacancies will promote the migration of Ag and $\mathrm{Pt}$ atoms significantly, to form tube-like structure. As the reaction proceeds, the concentration of the $\mathrm{Pt}^{4+}$ will decrease significantly, which slows down the replacement reaction, providing the time for the atom diffusion and coalescence via Oswald ripening, to counter the increase of the surface energy. Through enough time for the reorganization of $\mathrm{Pt}$ atoms, uniform $\mathrm{Pt}$ dendritic tubes with continuous single crystalline Pt shells are formed. After thorough wash of the sample to remove $\mathrm{AgCl}$ and the left of $\mathrm{Ag}$, pure Pt dendritic tubes are finally obtained (Figure S9d).

The highly improved activity of the Pt dendritic tubes, compared with commercial catalyst (Pt nanoparticles on carbon black), can be attributed to the following reasons: (1) the changes in the geometry and morphology ( $3 \mathrm{D}$ vs. $0 \mathrm{D}$ ) because the $3 \mathrm{D}$ shape facilitates the reaction kinetics and electron transport and also improves the diffusion of $\mathrm{O}_{2}$ to Pt surface; (2) the porous and hollow structure, which not only provides a large surface area for high catalyst utilization, but also improves the mass transport and gas diffusion ${ }^{27,28}$; and (3) fewer surface defects borne by the dendritic tubes, which bear a closer resemblance to the smooth single-crystalline bulk catalyst surface that have been proved to exhibit much higher ORR specific activities, for example, $\mathrm{Pt}$ (111) surface is 9 times more active than the current state-of-the-art $\mathrm{Pt} / \mathrm{C}$ catalysts in $\mathrm{PEMFCs}^{29}$. The ORR is a multielectron reaction $\left(\mathrm{O}_{2}+4 \mathrm{H}^{+}+4 \mathrm{e}^{-}=2 \mathrm{H}_{2} \mathrm{O}\right)$ that may include a number of elementary steps involving different reaction intermediates $^{49}$. Some charged oxygen atoms react with protons to create hydroxide molecules $\left(2 \mathrm{H}_{2} \mathrm{O}=\mathrm{OH}_{\mathrm{ad}}+\mathrm{H}_{3} \mathrm{O}^{+}+\mathrm{e}^{-}\right.$, where $\mathrm{OH}_{\mathrm{ad}}$ is the adsorbed hydroxyl layer) and likely other oxides as well. These oxides have an affinity for Pt atoms, binding to their surface, and block access to as many as $45 \%$ of the $\mathrm{Pt}$ atoms ${ }^{46}$. Given that $\Theta_{\mathrm{OHad}}$ is greatly weakened on Pt dendritic tube surface (as show in Figure 5a,b), the key factor that determines the excellent catalytic activity of $\mathrm{Pt}$ dendritic tubes is the low coverage by $\mathrm{OH}_{\mathrm{ad}}$. That means there are much fewer $\mathrm{OH}_{\mathrm{ad}}$ bind to Pt surface, leaving much more free Pt sites open to carry out oxygen reduction reactions ${ }^{50,51}$.

In order to further demonstrate the excellent electrochemical stability of Pt dendritic tubes, the changes of their morphology were investigated by TEM before and after ADT cycling (Figure 3 and Figure S10). The overall structure of the dendritic tubes retained largely intact, although the surface topology has slight change with occasionally broken in some parts (Figure S10a). HRTEM study indicates that the surface of these Pt tubes became smooth and the population of surface bump diminished after the multiple cycles, while most of the Pt primary crystals of the continues shell still keep the same orientation (Figure S10b). The significant improvement of the stability for dendritic Pt tubes is mainly attributed to the following reasons: 1) the less hydroxyl coverage (i.e. less Pt oxides formation) on large single crystal surface (large radii of curvature) of dendritic nanotubes pulls less Pt atoms off from the catalyst surface, drastically enhancing the catalyst stability; 2) the hierarchical structures, with strong mechanical property, decrease the detachment (drop-off), dissolution and aggregation of $\mathrm{Pt}$ from the dendritic matrix; 3 ) the larger radii of curvature of $\mathrm{Pt}$ shells make them more resistant to surface area loss via mechanisms such as Pt dissolution and re-deposition ${ }^{30}$; and 4) the elimination of corrosion of the catalyst support (e.g., carbon) due to the capability of self-supporting of micrometrelong Pt dendritic tubes. 
In conclusion, porous Pt dendritic nanotubes have been successfully synthesized by a simple, cost-effective, aqueous solution method based on the galvanic replacement reaction between $\mathrm{Ag}$ dendrites and $\mathrm{H}_{2} \mathrm{PtCl}_{6}$. The synthesis is green and environmentally benign, as it does not require high temperature, organic solvents, or electrochemical deposition. The porous Pt dendritic nanotubes were 2.33-fold more active on the basis of equivalent Pt mass, 4.4-fold more active in terms of specific activity for ORR than the state-ofthe-art Pt/C commercial catalyst, 5.25-fold more active on the basis of equivalent Pt mass and 3.68-fold more active in terms of their specific activity than the first-generation supportless Pt black catalyst. Moreover, the porous Pt dendritic nanotubes were 6.1-fold and 4.8-fold more stable than the $\mathrm{Pt} / \mathrm{C}$ and Pt black catalysts, respectively. Further enhancement of the ORR activity and stability is expected through the optimization of the morphology (shape and wall-thickness) and composition (alloys) of the porous dendritic nanotubes by varying the experimental parameters and adding other elements (e.g., Au and $\mathrm{Ni}$ ) to form alloys. Our work provides a promising approach for the design of highly active and stable next-generation catalysts with a substantial reduction in Pt loading without compromising performance. Porous Pt dendritic nanotubes may also be useful in catalysis applications beyond fuel cells.

\section{Methods}

Chemicals. Doubly distilled deionized (DI) water was used for all preparations. Silver nitrate $\left(\mathrm{AgNO}_{3}, 99.95 \%\right)$ and hexachloroplatinic acid $\left(\mathrm{H}_{2} \mathrm{PtCl}_{6} \cdot 6 \mathrm{H}_{2} \mathrm{O}, 99.95 \%\right)$ were obtained from Sigma-Aldrich and used as received. The magnesium metal powder $(\mathrm{Mg},-100+200$ mesh, 99.6\%) was obtained from Alfa Aesar. Commercial Pt/C (E-TEK, 30 wt\% Pt nanoparticles on Vulcan XC-72 carbon) and Pt black (fuel cell grade) catalysts were obtained from Sigma-Aldrich.

Synthesis. To synthesize Ag dendrites, a controlled amount of freshly prepared $\mathrm{AgNO}_{3}$ aqueous solution was quickly added to a glass vial that contained a predetermined amount of commercially available $\mathrm{Mg}$ powder. For example, the replacement reaction between $\mathrm{Mg}(5.3 \mathrm{mg})$ and $\mathrm{AgNO}_{3}$ solution $(0.03 \mathrm{M}, 17 \mathrm{ml})$ was used, in which the atomic concentration of $\mathrm{Ag}^{+}$was over 2-fold greater than that of $\mathrm{Mg}$, so that the $\mathrm{Mg}$ would be completely oxidized to $\mathrm{Mg}^{2+}$ and precipitate only $\mathrm{Ag}$ dendrites. The reactions were conducted in glass vials $(20 \mathrm{ml})$ at $12^{\circ} \mathrm{C}$ in ambient atmosphere for several minutes. The temperature was controlled by a constant temperature bath (VWR model 1162A). After the reduction reactions were completed, the products were washed several times in DI water, collected by filtration and then dried in a vacuum oven overnight. The synthesis of Pt dendritic tubes was conducted at room temperature via the replacement reaction between the Ag dendrites $(47 \mathrm{mg})$ and the $\mathrm{H}_{2} \mathrm{PtCl}_{6}$ solution $(0.06 \mathrm{M}, 2.8 \mathrm{ml})$. The solution color gradually changed from golden to nearly colorless, indicating the completion of the reaction; then, the $\mathrm{Pt}$ dendritic tubes were thoroughly washed using saturated $\mathrm{NaCl}$ and $\mathrm{HNO}_{3}$ to remove $\mathrm{AgCl}$ and $\mathrm{Ag}$, respectively, generating pure product.

Characterization. The morphologies, crystallinities, and chemical compositions of the samples were determined by a field-emission scanning electron microscope (FESEM, Hitachi S-4800, operating at $5 \mathrm{kV}$ ), which was equipped with an energydispersive X-ray spectrometer (EDX), a transmission electron microscope (TEM, Hitachi 7000, operating at $100 \mathrm{kV}$ ), and a high-resolution TEM (HRTEM, JEOL $2010 \mathrm{~F}$, operating at $200 \mathrm{kV}$ ). Powder X-ray diffraction (XRD) measurements were performed on a Bruker D8 Discover diffractometer operating at $40 \mathrm{kV}$ and $40 \mathrm{~mA}$ with $\mathrm{Cu} \mathrm{K} \alpha$ radiation $(\lambda=0.154 \mathrm{~nm})$.

Electrochemical measurements. Prior to the deposition of the catalyst onto the electrode surface for electrocatalytic assessment, a glassy carbon (GC) electrode (5 mm diameter) was polished with $\mathrm{Al}_{2} \mathrm{O}_{3}$ paste $(0.05 \mu \mathrm{m})$ and washed ultrasonically in double-distilled water. To prepare the catalyst suspension, the Pt dendritic nanotubes were first dispersed in a $5 \mathrm{~mL}$ aqueous solution containing $1 \mathrm{~mL}$ of isopropanol and $30 \mu \mathrm{L}$ of $5 \mathrm{wt} \%$ Nafion solution $\left(\mathrm{V}_{\text {water }}: \mathrm{V}_{\text {propanol }}: \mathrm{V}_{\text {Nafion }}=4 / 1\right.$ / 0.0017 in volume ratio) via sonication for $12 \mathrm{~min}$. Then, $10 \mu \mathrm{L}$ of the catalyst suspension was cast onto the clean GC electrode and dried under flowing $\mathrm{N}_{2}$ at room temperature, leading to a Pt loading of $7 \mu \mathrm{g}_{\mathrm{Pt}}$. The electrochemical properties were measured on an Autolab potentiostat/galvanostat (Model, PGSTAT-30, Ecochemie, Brinkman Instruments) with rotation control (MSR, Pine Instruments) using a threeelectrode system. The GC rotating disk electrode (RDE) on which the catalyst was loaded was used as working electrode. A Pt wire and $\mathrm{Ag} / \mathrm{AgCl}(3 \mathrm{M} \mathrm{NaCl})$ were used as the counter and reference electrodes, respectively. For convenience, all potentials in this study are referenced to the reversible hydrogen electrode (RHE). The solutions were de-aerated by bubbling ultra-high-purity $\mathrm{N}_{2}$ for $20 \mathrm{~min}$ and protected with a nitrogen atmosphere during the entire experimental procedure. All electrochemical experiments were carried out at room temperature.
For comparison, the commercial Pt/C (30 wt\% Pt, E-TEK) and Pt black catalyst suspensions were prepared following a similar protocol (i.e., in a mixture of distilled water, isopropanol, and $5 \mathrm{wt} \%$ Nafion solution, $\mathrm{V}_{\text {water }}: \mathrm{V}_{\text {propanol }}: \mathrm{V}_{\text {Nafion }}=$ $4: 1: 0.0017)$ and sonicated for $12 \mathrm{~min}$. An aliquot of the catalyst suspension was pipetted onto the GC electrode, leading to a Pt loading of $7 \mu \mathrm{g}_{\mathrm{Pt}}$ for all catalysts. The catalyst films were dried under flowing $\mathrm{N}_{2}$ at room temperature. All of the testing conditions and parameters were the same as those used for the Pt dendritic nanotubes.

Before collecting the effective cyclic voltammetry $(\mathrm{CV})$ measurements, the working electrode was first cycled between 0 and $1.2 \mathrm{~V}$ at $50 \mathrm{mV} / \mathrm{s}$ for 50 cycles in an $\mathrm{N}_{2}$ purged $0.5 \mathrm{M} \mathrm{H}_{2} \mathrm{SO}_{4}$ solution at room temperature, to produce a clean electrode surface. The electrochemical surface areas (ECSA) were calculated by measuring the charge associated with the $\mathrm{H}_{\text {ads }}\left(Q_{\mathrm{H}}\right)$ between 0 and $0.4 \mathrm{~V}$ and assuming that $Q_{\text {ref }}=0.21 \mathrm{mC} / \mathrm{cm}^{2}$, corresponding to a surface density of $1.3 \times 10^{15} \mathrm{Pt}$ atoms per $\mathrm{cm}^{2}$, which is generally accepted for polycrystalline Pt electrodes. The ECSA of the Pt was calculated based on the following relationship:

$$
E C S A=Q_{\mathrm{H}} /\left(Q_{\text {ref }} \times \mathrm{m}\right)
$$

where $Q_{H}$ is the charge for $\mathrm{H}$ adsorption $\left(\mathrm{mC} / \mathrm{cm}^{2}\right)$, $\mathrm{m}$ is the $\mathrm{Pt}$ loading $\left(\mathrm{mg} / \mathrm{cm}^{2}\right)$ in the electrode, and $Q_{\text {ref }}$ is the charge required for the adsorption of a hydrogen monolayer on a Pt surface $\left(0.21 \mathrm{mC} / \mathrm{cm}^{2}\right)^{43}$. The adsorption of hydroxyl species was calculated based on the $\mathrm{OH}_{\text {ad }}$ peak in the $\mathrm{CV}$ curves at a potential higher than $0.6 \mathrm{~V}$ (vs. RHE). Dividing the hydroxyl adsorption area by the overall active surface area produced the surface coverage of the $\mathrm{OH}_{\mathrm{ad}}$ species $\left(\Theta_{\mathrm{OHad}}\right)^{45}$. The oxygen reduction reaction (ORR) experiments were performed in an $\mathrm{O}_{2}$-saturated $0.5 \mathrm{M} \mathrm{H}_{2} \mathrm{SO}_{4}$ solution at room temperature with an $\mathrm{RDE}$ rotating rate of $1,600 \mathrm{rpm}$ and a sweep rate of $10 \mathrm{mV} / \mathrm{s}$. The current densities were normalized to the geometric area of the GC RDE $\left(0.196 \mathrm{~cm}^{2}\right)$. The CV measurements for the accelerated durability test (ADT) were conducted by potential cycling between 0.6 and $1.2 \mathrm{~V}$ (vs. RHE) for 4,000 cycles in $\mathrm{O}_{2}$-saturated $0.5 \mathrm{M} \mathrm{H}_{2} \mathrm{SO}_{4}$ at room temperature at a scan rate of $50 \mathrm{mV} / \mathrm{s}$. The full-scale voltammograms between 0 and $1.2 \mathrm{~V}$ in $\mathrm{N}_{2}$-saturated $0.5 \mathrm{M}$ $\mathrm{H}_{2} \mathrm{SO}_{4}$ were recorded periodically to track the degradation of the Pt catalysts.

1. Steele, B. C. H. \& Heinzel, A. Materials for fuel-cell technologies. Nature 414, 345-352 (2001).

2. Perry, M. L. \& Fuller, T. F. A Historical Perspective of Fuel Cell Technology in the 20th Century. J. Electrochem. Soc. 149, S59-S67 (2002).

3. Joo, S. H. et al. Ordered nanoporous arrays of carbon supporting high dispersions of platinum nanoparticles. Nature 412, 169-172 (2001).

4. Lim, B. et al. Facile Synthesis of Highly Faceted Multioctahedral Pt Nanocrystals through Controlled Overgrowth. Nano Lett. 8, 4043-4047 (2008).

5. Wang, C., Daimon, H., Lee, Y., Kim, J. \& Sun, S. Synthesis of Monodisperse Pt Nanocubes and Their Enhanced Catalysis for Oxygen Reduction. J. Am. Chem. Soc. 129, 6974-6975 (2007).

6. Wang, C., Daimon, H., Onodera, T., Koda, T. \& Sun, S. A General Approach to the Size- and Shape-Controlled Synthesis of Platinum Nanoparticles and Their Catalytic Reduction of Oxygen. Angew. Chem. Int. Ed. 47, 3588-3591 (2008).

7. Sun, S., Jaouen, F. \& Dodelet, J. Controlled Growth of Pt Nanowires on Carbon Nanospheres and Their Enhanced Performance as Electrocatalysts in PEM Fuel Cells. Adv. Mater. 20, 3900-3904 (2008)

8. Sun, S. et al. A Highly Durable Platinum Nanocatalyst for Proton Exchange Membrane Fuel Cells: Multiarmed Starlike Nanowire Single Crystal. Angew. Chem. Int. Ed. 50, 422-426 (2011).

9. Sun, S. et al. Ultrathin single crystal Pt nanowires grown on N-doped carbon nanotubes. Chem. Commun. 45, 7048-7050 (2009).

10. Lim, S. I. et al. Synthesis of Platinum Cubes, Polypods, Cuboctahedrons, and Raspberries Assisted by Cobalt Nanocrystals. Nano Lett. 10, 964-973 (2010).

11. Lu, X. et al. Noble-Metal Nanotubes Prepared via a Galvanic Replacement Reaction Between $\mathrm{Cu}$ Nanowires and Aqueous $\mathrm{HAuCl}_{4}, \mathrm{H}_{2} \mathrm{PtCl}_{6}$, or $\mathrm{Na}_{2} \mathrm{PdCl}_{4}$. Sci. Adv. Mater. 2, 413-420 (2010).

12. Chang, L. Y., Barnard, A. S., Gontard, L. C. \& Dunin-Borkowski, R. E. Resolving the Structure of Active Sites on Platinum Catalytic Nanoparticles. Nano Lett. 10, 3073-3076 (2010).

13. Cui, C., Li, H. \& Yu, S. A general approach to electrochemical deposition of high quality free-standing noble metal (Pd, Pt, Au, Ag) sub-micron tubes composed of nanoparticles in polar aprotic solvent. Chem. Commun. 46, 940-942 (2010).

14. Sun, Y., Mayers, B. \& Xia, Y. Metal Nanostructures with Hollow Interiors. Adv. Mater. 15, 641-646 (2003).

15. Bai, F. et al. Templated photocatalytic synthesis of well-defined platinum hollow nanostructures with enhanced catalytic performance for methanol oxidation. Nano Lett. 11, 3759-3762 (2011).

16. Bi, Y. \& Lu, G. Control growth of uniform platinum nanotubes and their catalytic properties for methanol electrooxidation. Electrochem. Commun. 11, 45-49 (2009).

17. Chen, Z., Waje, M., Li, W. \& Yan, Y. Supportless Pt and PtPd Nanotubes as Electrocatalysts for Oxygen-Reduction Reactions. Angew. Chem. Int. Ed. 119, 4138-4141 (2007).

18. Liu, H. et al. Hollow and cage-bell structured nanomaterials of noble metals. J. Am. Chem. Soc. 134, 11602-11610 (2012).

19. Alia, S. M. et al. Porous Platinum Nanotubes for Oxygen Reduction and Methanol Oxidation Reactions. Adv. Funct. Mater. 20, 3742-3746 (2010). 
20. Koczkur, K., Yi, Q. \& Chen, A. Nanoporous Pt-Ru Networks and Their Electrocatalytical Properties. Adv. Mater. 19, 2648-2652 (2007).

21. Liu, X., Lin, Y., Zhou, S., Sheehan, S. \& Wang, D. Complex Nanostructures: Synthesis and Energetic Applications. Energies 3, 285-300 (2010).

22. Zhou, S., Liu, X., Lin, Y. \& Wang, D. Spontaneous Growth of Highly Conductive Two-Dimensional Single-Crystalline $\mathrm{TiSi}_{2}$ Nanonets. Angew. Chem. Int. Ed. 47, 7681-7684 (2008).

23. Yang, Y. \& Meng, G. Ag dendritic nanostructures for rapid detection of polychlorinated biphenyls based on surface-enhanced Raman scattering effect. J. Appl. Phys. 107, 044315-044315-5 (2010).

24. Fan, L. \& Guo, R. Growth of Dendritic Silver Crystals in CTAB/SDBS MixedSurfactant Solutions. Crystal Growth \& Design 8, 2150-2156 (2008).

25. Takai, A., Yamauchi, Y. \& Kuroda, K. Fabrication of mesoporous Pt nanotube utilizing dual templates under a reduced pressure condition. Chem. Commun. 35, 4171-4173 (2008)

26. Kijima, T. et al. Noble-Metal Nanotubes (Pt, Pd, Ag) from Lyotropic MixedSurfactant Liquid-Crystal Templates. Angew. Chem. Int. Ed. 43, 228-232 (2003).

27. Choi, W. S., Koo, H. Y., Zhongbin, Z., Li, Y. \& Kim, D. Templated Synthesis of Porous Capsules with a Controllable Surface Morphology and their Application as Gas Sensors. Adv. Funct. Mater. 17, 1743-1749 (2007).

28. Zhong, L. et al. Self-Assembled 3D Flowerlike Iron Oxide Nanostructures and Their Application in Water Treatment. Adv. Mater. 18, 2426-2431 (2006).

29. Stamenkovic, V. R. et al. Improved Oxygen Reduction Activity on $\mathrm{Pt}_{3} \mathrm{Ni}(111)$ via Increased Surface Site Availability. Science 315, 493-497 (2007).

30. Debe, M. K. Electrocatalyst approaches and challenges for automotive fuel cells. Nature 486, 43-51 (2012).

31. Yin, Y. et al. Formation of Hollow Nanocrystals Through the Nanoscale Kirkendall Effect. Science 304, 711-714 (2004).

32. Cabot, A. et al. Vacancy Coalescence during Oxidation of Iron Nanoparticles. J. Am. Chem. Soc. 129, 10358-10360 (2007).

33. Fan, H. J. et al. Monocrystalline spinel nanotube fabrication based on the Kirkendall effect. Nature Materials 5, 627-631 (2006).

34. González, E., Arbiol, J. \& Puntes, V. F. Carving at the Nanoscale: Sequential Galvanic Exchange and Kirkendall Growth at Room Temperature. Science 334, 1377-1380 (2011).

35. Schmidt, T. J. et al. Characterization of High-Surface-Area Electrocatalysts Using a Rotating Disk Electrode Configuration. J. Electrochem. Soc. 145, 2354-2358 (1998)

36. Lim, B. et al. Pd-Pt Bimetallic Nanodendrites with High Activity for Oxygen Reduction. Science 324, 1302-1305 (2009).

37. Peng, Z. \& Yang, H. Synthesis and Oxygen Reduction Electrocatalytic Property of Pt-on-Pd Bimetallic Heteronanostructures. J. Am. Chem. Soc. 131, 7542-7543 (2009).

38. Service, R. F. Platinum in Fuel Cells Gets a Helping Hand. Science 315, 172-172 (2007).

39. Gasteiger, H. A. \& Ross, P. N. Oxygen Reduction on Platinum Low-Index SingleCrystal Surfaces in Alkaline Solution: Rotating Ring Disk $\mathrm{pt}_{\mathrm{thkl})}$ Studies. J. Phys. Chem. 100, 6715-6721 (1996).

40. US Department of Energy. Research and Development of Fuel Cells for Stationary and Transportation Applications: Topic 5 Catalysts/Electrodes(www.fedconnect. net $/$ FedConnect/?doc $=$ DE-FOA-0000360\&agency $=$ DOE 12/22/2010).

41. Zhang, G. et al. Morphology-Controlled Green Synthesis of Single Crystalline Silver Dendrites, Dendritic Flowers, and Rods, and Their Growth Mechanism. Crystal Growth \& Design 11, 2493-2499 (2011).
42. Zoski, C. G. Handbook of Electrochemistry. pp. 815-817 (Elsevier: 2007).

43. Weidner, J. Battery/Energy Technology (General): ECS Transactions: Volume 11. p. 96 (The Electrochemical Society: 2008).

44. Sieradzki, K. Curvature Effects in Alloy Dissolution. J. Electrochem. Soc. 140 2868-2872 (1993).

45. Wang, Z. L., Ahmad, T. S. \& El-Sayed, M. A. Steps, ledges and kinks on the surfaces of platinum nanoparticles of different shapes. Surface Science 380, 302-310 (1997).

46. Lu, X. et al. Mechanistic Studies on the Galvanic Replacement Reaction between Multiply Twinned Particles of $\mathrm{Ag}$ and $\mathrm{HAuCl}_{4}$ in an Organic Medium. J. Am. Chem. Soc. 129, 1733-1742 (2007).

47. Zhang, G. et al. Large-Scale Aqueous Synthesis and Growth Mechanism of SingleCrystalline Metal Nanoscrolls at Room Temperature: The Case of Nickel. Chem. Mater. 22, 4721-4727 (2010).

48. Zhang, G. et al. Controlled Growth/Patterning of Ni Nanohoneycombs on Various Desired Substrates. Langmuir 26, 4346-4350 (2010).

49. Markovic, N. M., Gasteiger, H. A. \& Ross, P. N. Oxygen Reduction on Platinum Low-Index Single-Crystal Surfaces in Sulfuric Acid Solution: Rotating RingPt $(h k l)$ Disk Studies. J. Phys. Chem. 99, 3411-3415 (1995).

50. Zhang, J. et al. Platinum Monolayer Electrocatalysts for $\mathrm{O}_{2}$ Reduction: $\mathrm{Pt}$ Monolayer on Pd(111) and on Carbon-Supported Pd Nanoparticles. J. Phys. Chem. B 108, 10955-10964 (2004).

51. Zhang, J., Vukmirovic, M. B., Xu, Y., Mavrikakis, M. \& Adzic, R. R. Controlling the Catalytic Activity of Platinum-Monolayer Electrocatalysts for Oxygen Reduction with Different Substrates. Angew. Chem. Int. Ed. 117, 2170-2173 (2005).

\section{Acknowledgments}

This work was supported by GM of Canada, NSERC, The CRC Program, CFI, ORF, ERA and UWO. G.Z. is grateful to the NSERC postdoctoral fellowship. S.S. is grateful to the Alexander Graham Bell Canada Graduate Scholarships (NSERC CGS D).

\section{Author contributions}

G.Z. and S.S. performed the catalyst preparation, characterizations and performance tests. G.Z. and R.L. contributed to TEM characterization. Y.Z. contributed to schematic design S.S. and G.Z. designed the study, analyzed the data and co-wrote the paper. X.S. and M.C. proposed, planned and supervised the project. All the authors participated in the discussion of the research and commented on the manuscript.

\section{Additional information}

Supplementary information accompanies this paper at http://www.nature.com/ scientificreports

Competing financial interests: The authors declare no competing financial interests.

License: This work is licensed under a Creative Common

Attribution-NonCommercial-NoDerivs 3.0 Unported License. To view a copy of this license, visit http://creativecommons.org/licenses/by-nc-nd/3.0/

How to cite this article: Zhang, G. et al. Porous Dendritic Platinum Nanotubes with Extremely High Activity and Stability for Oxygen Reduction Reaction. Sci. Rep. 3, 1526; DOI:10.1038/srep01526 (2013) 